\title{
Depletion of high mobility group box 1(HMGB1) in dendritic cells (DCs) suppresses tumorigenesis and promotes viral clearance
}

\author{
Wenqian Wang ${ }^{1 *}$, Philip Vernon², Guanqiao Li $i^{1}$, Padmavathi Sampath ${ }^{3}$, Thorne Stephen ${ }^{3}$, Xiaoyan Liang ${ }^{4}$, \\ Michael Lotze ${ }^{5}$
}

From Society for Immunotherapy of Cancer 29th Annual Meeting

National Harbor, MD, USA. 6-9 November 2014

\section{Introduction}

HMGB1, an evolutionarily ancient and abundant DNAbinding protein within the nucleus, acts as a Damage Associated Molecular Pattern (DAMP) molecule extracellularly to promote immunity. During both cellular stress and immune cell activation, it is translocated into the cytosol and enhances autophagic flux. DCs are critical to both initiating and maintaining $\mathrm{T}$ cell adaptive immunity in human cancers. As such, they have formed the basis of many anti-tumor immunotherapies aimed at directing responses to tumor-associated antigens. Vaccinia virus, a large, enveloped virus with dsDNA genome, can infect DCs and inhibit DC maturation. HMGB1 is required for DC functionality and chemotaxis but how HMGB1 regulates DC function in anti-tumor immune response and viral clearance remains unclear.

\section{Methods}

Mice with HMGB1 specifically knocked-out in DCs (DCH) were generated by crossing HMGB1 floxed mice with CD11c Cre mice. For subcutaneous tumor model, wide type (WT), flox/flox and DCH mice were inoculated with $5 \times 10^{5}$ Panc02 murine pancreatic cancer cells and $5 \times 10^{5}$ MC38 murine colorectal cancer cells. For the bone marrow (BM) transplant model, 8 week old Pdx1-Cre: KrasG12D/+(KC mice) were reconstituted via tail vain injection of $1 \times 10^{6}$ freshly isolated BM cells from either DCH or WT after BM progenitor depletion via 1000rad gamma-irradiation. For the virus model, WT and DCH mice were injected with $1 \times 10^{7}$ luc+ vaccinia virus.

'Departments of Surgery and Immunology, University of Pittsburgh; School of Medicine, Tsinghua University, USA

Full list of author information is available at the end of the article

\section{Results}

While tumors readily grew in both WT and flox/flox mice, the growth was significantly suppressed in $\mathrm{DCH}$ mice following Panc02 cancer cell challenge $(\mathrm{p}<0.05)$. The similar inhibitory function was observed in the intrahepatic MC38 tumor model ( $\mathrm{p}<0.05)$. In BM transplant experiments, WT to $\mathrm{KC}$ chimeras showed both neoplastic ducts and extensive fibrogenesis. KC mice which had received DCH bone marrow exhibited near normal ductal morphology and a significantly diminished occurrence of both low and high grade PanIN lesions $(p<0.05)$ with reduced levels of myeloidderived suppressor cells (MDSCs), as well as decreased levels of nominal regulatory $\mathrm{T}$ cells (Tregs) in spleen and lower levels of infiltrating cells in pancreas $(\mathrm{p}<0.05)$. Although both WT and DCH mice cleared virus by day 7 following vaccinia virus injection, $\mathrm{DCH}$ mice displayed less virus replication and faster viral clearance $(\mathrm{p}<0.05)$. This is associated with increased T cells $(\mathrm{p}<0.01)$ and $\mathrm{CD} 11 \mathrm{c}+$ cells $(\mathrm{p}<0.05)$ within the spleen.

\section{Conclusion}

DC-specific HMGB1 knockout mice not only suppress carcinogenesis and tumor growth but also clear vaccinia viral infection more effectively. This has profound implications for understanding and targeting DCs and HMGB1 for therapy.

\footnotetext{
Authors' details

'Departments of Surgery and Immunology, University of Pittsburgh; School of Medicine, Tsinghua University, USA. ${ }^{2}$ Naval Medical Research Unit-San Antonio, USA. ${ }^{3}$ Departments of Immunology, University of Pittsburgh, PA, USA. ${ }^{4}$ Departments of Surgery, University of Pittsburgh, PA, USA. ${ }^{5}$ Departments of Surgery, Immunology and Bioengineering, University of Pittsburgh, PA, USA.
} 
Submit your next manuscript to BioMed Central and take full advantage of:

- Convenient online submission

- Thorough peer review

- No space constraints or color figure charges

- Immediate publication on acceptance

- Inclusion in PubMed, CAS, Scopus and Google Scholar

- Research which is freely available for redistribution

Submit your manuscript at www.biomedcentral.com/submit
() Biomed Central 